\title{
Environmental consciousness and choice of bulb for lighting in a developing country
}

\author{
Anthony Amoah*, George Hughes and Paragon Pomeyie
}

\begin{abstract}
Background: Most countries in the world especially those in Asia and Africa have been undertaking policies meant to help promote science, technology and innovation towards meeting some provisions of the Sustainable Development Goals. However, there is still a sizable number of households who have not yet fully embraced energy-saving technologies. This study provides highlights on the economic and environmental benefits for investing in energy-saving light bulbs.

Methods: Using a survey and a multistage random sampling approach, we administered questionnaires to 1650 households in Ghana. The relevant diagnostic tests associated with cross-sectional data were undertaken. We estimated a maximum-likelihood probit model with its associated marginal effects to find out how the choice of energy-saving light bulb (behaviour) is influenced by environmental consciousness (both local knowledge and global knowledge) and other demographic factors.
\end{abstract}

Results: Our results are consistent with economic theory as well as what earlier empirical evidence found in literature. That is, environmental consciousness, education, income, etc. are very important in explaining the choice of buying energy-saving light bulbs in Ghana.

Conclusions: Besides advocating for information that will make society more environmentally conscious, we further recommend the use of fiscal policies (i.e. subsidies) to support lower income brackets who are predominant in developing countries.

Keywords: Environmental consciousness, Environmental attitude, Light bulbs, CFLs, Electricity, Developing countries

\section{Background}

Emissions from the energy sector is a key driver of greenhouse gas emissions; howbeit, this is not without its associated impact on climate change. As a result, environmental management and promotion of energy efficiency have gained significant interest in global discourse. For example, in the Sustainable Development Goal (SDG) framework, science, technology and innovation (STI) have been recommended to promote efficient use of resources such as energy. Aside from the environmental impact, efficient utilization of energy (particularly electricity) is important in developing countries, where the sector is characterized by supply shortfalls resulting in intense outages.

In Ghana, for instance, a National Compact Fluorescent Exchange Programme was implemented in 2009 under

\footnotetext{
* Correspondence: aamoah@central.edu.gh

Central University, P.O. Box DS 2310, Dansoman-Accra, Ghana
}

the auspices of the Ministry of Energy. The primary objective of this programme was to save the nation of about 200-220 MW of electricity which hitherto would have been wasted. This was to be achieved through replacing six million incandescent lamps at zero opportunity cost. An evaluation of this policy in 2008 has shown some level of success. This includes peak load savings of $124 \mathrm{MW}$ or 172.8 GWh/annum (equivalent of US\$ 1,179,360), $\mathrm{CO}_{2}$ savings of about 112,320 tons per annum, mean household income savings of about GH\$31.00 in 25 districts nationwide over 6 months, a reduction of 148,000 barrels of light crude oil for thermal electricity generation, etc. However, this policy was not without its fallouts. A key setback to the implementation of the programme was "inadequate awareness creation on Compact Florescent Lamps (CFLs) technology for household beneficiaries" ([1], p.5). For this and other reasons, some households rejected the CFLs irrespective of the enormous benefits associated 
with it. ${ }^{1}$ Given the setbacks, it goes without saying that not all households have adopted this efficient technology hence not using energy-saving light bulbs. Coupled with the economic growth potential of Ghana which was about $14.0 \%$ in 2011, one would expect residential lighting consumption to rise in the coming years. We find this as a huge setback which calls for a research that borders on the extent to which environmental consciousness (awareness) can influence consumers' behaviour towards efficient energy use.

The purpose of the study is to find out whether there is still much room to reduce waste as a result of households' behaviour. Thus, our key research question is, "will an environmentally conscious household make a rational choice by buying CFLs that will help reduce waste instead of incandescent bulbs?" This is against the background assumption that consumers are likely to choose wrongly as a result of lack of awareness (see [2]). We posit that enhancing consumers' awareness and consciousness about the environment can help achieve $0 \%$ use of alternatives to clean energy-saving light bulbs. So, we hypothesize that environmental consciousness/ awareness through education has a statistically significant positive effect on the consumer's behaviour regarding the choice of electricity light bulbs. The main contribution of this study is to highlight the relevance of environmental consciousness in implementing sustainable energy programmes in developing countries.

First, we would like to acknowledge that there is paucity of literature on environmental consciousness/awareness and the choice of energy-saving light bulbs especially in developing countries. In the case of developed countries, Di Maria et al. [3] used the Urban Institute of Ireland's data to analyze attitudes and perception in their quest to shed light on the light bulb puzzle. In their paper, they first presented the theoretical propositions underlying the subject and further subjected it to empirical testing. They showed the relevance of CFLs by estimating the annual external cost associated with lighting to be about $€ 45-50$ billion. They argued further that low energy efficiency of the residential sector makes them responsible for about one third of this cost. Their work showed the relevance of environmental consciousness in adoption decision.

Another study by Ellen [4] asked a simple question: "do we know what we need to know?" In her study, she mainly sought to explore objective and subjective knowledge effects on pro-ecological behaviours and related attitudes. Her study used focus interviews which included 37 area citizens, university employees and students. Twostage random sampling technique was used for respondents who were at least 18 years. Her results showed that for consumers who are environmentally concerned, their objective knowledge regarding environmental issues is relatively low.
Asilsoy [5] acknowledges that urban residents who are environmentally conscious are expected to exhibit attitudes and behaviours that promote sustainable urbanism. Similarly, Kaynak and Ekşi [6] explored environmental consciousness and its associated effects on attitudes using a sample size of 504. They employed a structural equation model and concluded that environmental consciousness has a positive and significant impact on attitudes.

A more recent study by Sánchez et al. [7] on the topic "Improving Pro-environmental Behaviours in Spain. The Role of Attitudes and Socio-demographic and Political Factors" sought to determine by means of the structural equation model the extent to which socio-demographic, economic and political factors influence people's environmental attitudes vis a vis consumption and purchase behaviour of Spaniards. The authors made use of a survey data in 2007. As part of their findings, they had evidence that factors not limited to the level of environmental information/concern, age and education explain positively variation in pro-environmental-related behaviours.

Schlegelmilch et al. [8] have pointed out that there exist a variety of studies that cut across different disciplines such as psychology, sociology, political science, education, ${ }^{2}$ environmental studies and business research that have tried over four decades now to conceptualize and operationalize the construct of "environmental consciousness". So far, the literature has not been able to provide any cast-in-stone definition or measurement that is all encompassing in explaining environmental consciousness. Although Schlegelmilch et al. [8] have summarized the views as expressed by some authors as relatively comprehensive, however, they were quick to have cited Van Liere and Dunlap ([9]: p.653) who have pointed out that none of the "issues [or constructs] reflect equally the broader concept..." In sum, most of the approaches used in the literature have tried to conceptualize environmental consciousness; however, they are subjective and in a way are subjected to criticisms. That notwithstanding, in this paper, we define environmental consciousness as the degree of local or global environmental knowledge acquired by an individual, household or society that informs their environmental behaviour (external) or attitude (internal). Schlegelmilch et al. ([8]: p.4) provides some components of the construct of environmental consciousness to include (1) environmental attitudes [is described by Buttel [10], as "individuals' levels of concern/interest about specific or general aspects of environmental, ecological, or energy-saving phenomena"] and (2) environmentally sensitive behaviour [is described by Brooker [11], as "individuals' past, current and intentional commitment to activities that aim to ameliorate society's negative impact on the natural environment"]. Against this background, we argue that households that are environmentally conscious are likely to 
exhibit some of these components. For example, if a household is environmentally conscious, that household will be more likely to buy an energy-saving light bulb. However, we do not expect a similar behaviour from a household that is not environmentally conscious. Following our conservative definition of environmental consciousness, we acknowledge that in this study the term environmental consciousness is used interchangeably with environmental awareness.

\section{Methods}

\section{Data}

Household-level data from the Greater Accra Region (GAR) was used for the study. This region (made up of ten districts) $)^{3}$ is chosen because apart from it being the capital city with high access to electricity, it also dominates the other regions regarding the percentage increase in the share of households. With a total number of 766,955 urban households, we used the Yamane sample size formula as used by Amoah [12] to compute our sample size. Nonetheless, we oversampled in order to harness the benefits associated with large samples. The data was obtained with a standard questionnaire to a multistage random sampling technique of 1650 households with access to electricity from the national grid. This was achieved by dividing the region into ten strata (districts). We further sub-divided each stratum into their respective communities. These communities were listed given the Town and Country Planning list of communities. At the final stage, households in the listed communities were randomly selected and interviewed. One hundred four (104) communities from all the ten districts were used in the survey. The face-to-face survey yielded approximately $99 \%$ total response rate. In cases where the household was not willing to participate or absent at the time of visit, the next available household was interviewed.

Before the final drafting of the questionnaire, it was made available for survey experts and some relevant stakeholders to provide some reviews before the final draft. The final draft was presented at a seminar for further comments and inputs. The questionnaire was categorized into sections. Similar to Ghana's standard national survey questionnaire, we began with information to identify the respondent and his/her socio-economic characteristics. Unlike other geographical areas where this method is challenged, this sits well with the people of Ghana. We had another section on general questions about the environment which also included the environmental consciousness questions. The penultimate section asked residential characteristics and choice or preference for attributes of the residence which included the choice of light bulbs used in residence. The last section included questions which allowed us to evaluate our instruments used for the survey. Using 25 field administrators in
2014, the survey lasted for about 3 months (March-May) which included training, pilot survey and data entry. We do not expect the period of the survey to have any influence on the behaviour of households regarding their choice of light bulbs.

\section{Econometric technique}

Our dependent variable was obtained from households responding to a survey question: "What type of electricity bulb is your household currently using?" This captures past purchase and current use behaviours as discussed by Brooker [11]. The authors reduced the categories (similar to [13]) ${ }^{4}$ into households who reported to be using energy-saving/efficient light bulbs or incandescent (energyinefficient light bulbs). The former and latter were coded as 1 and 0 , respectively. Given that the region has peak household electricity consumption periods to be mornings (6-10 am) and evenings (6-10 pm), one would expect majority of households to behave rationally and use lights within this period. We admit that our design excludes lights that are switched on occasionally as it may not be consistent with observed rational behaviour. Indeed, the binary series provided the opportunity to use a probit model given the binary nature of the dependent variable. In line with Di Maria et al. [3], we specify our probit model (as Eq. 1) which indicates the probability of choosing a light bulb which could either be an energysaving light bulb or an energy-inefficient light bulb as a function of environmental consciousness (i.e. a vector) and controls. These controls include logarithm of income, gender (male), logarithm of rent per month, education and district dummies.

$$
\begin{aligned}
& P(\text { Bulb Choice }[y]=1 \mid X) \\
& \quad=f\left(\beta_{0}+\beta_{1} \text { Env.Cosciousness }+\beta_{2} \text { Controls }\right)
\end{aligned}
$$

The log-likelihood function of our probit model is also specified as:

$$
\begin{aligned}
& \log L=\left[\sum_{i=1}^{n}\left[y_{i} \ln \left(\Phi\left(\beta_{0}+\beta_{0} X_{i}\right)\right)+\left(1-y_{i}\right)\right]\right. \\
& \left.\ln \left(1-\Phi\left(\beta_{0}+\beta_{1} X_{i}\right)\right)\right]
\end{aligned}
$$

Given that the index of the coefficient of the probit model is different from the marginal effects, we present the marginal effect of our probit model as Eq. 3:

$$
\frac{\partial E\left(y_{i} \mid x_{i}\right)}{\partial x_{i}}=\left\{\frac{d F\left[\beta^{\prime} x_{i}\right]}{d\left(\beta^{\prime} x_{i}\right)}\right\} \beta_{i}
$$

Our variable of interest which is environmental consciousness was disaggregated into two categories, namely international (inter.)/global knowledge and local knowledge. Regarding the former, the question asked was "[w]hich of 
the following international environmental issues do you know of?" The main options available to the respondent included global warming/greenhouse gases, climate change, Kyoto Protocol... Respondents were to choose YES if they had knowledge of the option provided and NO if otherwise. For the latter, the question asked was "[m]ention any National/District/Local environmental law/policy/practice you know of?" Respondents who were able to mention any were deemed to have knowledge (YES) and the reverse is true. Thereafter, the principal component analysis (see Appendix) was used to select which of the variables to use as the proxy. Further, we conducted a parametric test (see Tables 4 and 5 in Appendix) of household choice of light bulb by our variables of interest (i.e. local and international). In both cases, we found a statistically significant difference between the choices and environmental knowledge. We acknowledge that the binary option is to a larger extent limited relative to ordinal series. Nonetheless, it does not erode the validity of our conclusion. These variables of interest and other controls used in the model are descriptively presented in Table 1.

From Table 1, the average number of people using energy-saving light bulbs is about $86 \%$, a figure that confirms the significant impact of the light bulb exchange programme as reported by the Ministry of Energy in 2011. To buttress our finding, the United Nations Environment Programme (UNEP) [14] has reported a survey conducted on Ghana in 2009 that penetration of energy-saving light bulbs has increased from 3 to $79 \%$. Sixty-one percent and $56 \%$ had knowledge about climate change and domestic environmental policy respectively. This suggests that although a greater fraction of the respondents have knowledge about the environment, quite a good number are also ignorant which requires more education on environmental or green-related matters. The reported households' average monthly income of GHS 636.37 is quite close to the GHS5 44 reported for GAR by the Ghana Statistical Service (GSS) in 2008. Household decision making in Ghana is mainly the responsibility of men. It is therefore not surprising that $89 \%$ of the respondents are males. Also, the average rent paid by respondents is GHS 140.39 per month. Lastly, we observed that 59\% of the respondents were educated.

\section{Diagnostic tests}

Table 2 shows the pairwise correlation matrix for all variables used in the econometric model for our estimation. The test shows the correlation coefficient, the associated $p$ values (to determine the level of significance) and the total number of observations used for the estimation. Using a $p$ value of $1 \%$, we have evidence of no high pair of variables in our model. Stated differently, as given by our evidence, there is no severe multi-collinearity in the model that can affect our variances and co-variances which can also affect the precision of our estimation. However, we acknowledge that the correlation between rent and income reports the highest correlation coefficient of 0.47, yet this is not high enough to inflate our estimates.

Arguably, environmental knowledge (consciousness/ awareness) is endogenous as it is likely to be correlated with unobserved and observable determinants of household's behaviour. However, finding a good instrument for environmental knowledge is an empirical challenge due to data constraints. This poses a challenge to the causal identification of the impact of the environmental knowledge on the households' behaviour. Hence, our estimates should be interpreted as association/correlation rather than causal (see [15]).

Additional diagnostic tests were conducted on the model. Thus, the probit model was estimated with robust standard errors which control for possible heteroscedasticity in the model. Furthermore, we included all district dummies (with district 10 as the reference category) to cater for possible differences or unobserved heterogeneity amongst the districts (see [16, 17]). Against this background, we are confident of our estimates as presented in Table 3.

Table 1 Descriptive statistics

\begin{tabular}{|c|c|c|c|c|c|c|}
\hline Variables & Description & Obs. & Mean [\%] & Std. dev. & Min & Max \\
\hline${ }^{*}$ Choice of light bulbs (choice) & Energy-saving light bulbs only $=1$, otherwise $=0$ & 1604 & 0.87 [87\%] & 0.34 & 0 & 1 \\
\hline *Inter. knowledge & Yes $=1, \mathrm{no}=0$ & 1604 & $0.61[61 \%]$ & 0.49 & 0 & 1 \\
\hline *Dom. env. knowledge & Yes $=1, n o=0$ & 1604 & $0.56[56 \%]$ & 0.50 & 0 & 1 \\
\hline Household income & Amount in Ghana Cedis (GHS) & 1604 & 636.37 & 581.35 & 160 & 4400 \\
\hline Household income (log) & Amount in Ghana Cedis (GHS) & 1604 & 6.13 & 0.78 & 5.08 & 8.39 \\
\hline Male & Male $=1$, female $=0$ & 1604 & 0.89 [89\%] & 0.32 & 0 & 1 \\
\hline Rent per month & Amount in Ghana Cedis (GHS) & 1604 & 140.39 & 176.00 & 10 & 1000 \\
\hline Rent per month (log) & Amount in Ghana Cedis (GHS) & 1604 & 4.41 & 0.98 & 2.30 & 6.91 \\
\hline Education & Educated $=1$, not educated $=0$ & 1604 & 0.59 [59\%] & 0.49 & 0 & 1 \\
\hline
\end{tabular}

Obs. observations

*More description of these key variables are provided in the "Econometric technique" section 
Table 2 Pairwise correlation matrix

\begin{tabular}{|c|c|c|c|c|c|c|c|}
\hline & Choice & Int. knowl & Loc. knowl & $\mathrm{HH}$ income & Male & Rent & Education \\
\hline Choice & 1.0000 & & & & & & \\
\hline$p$ values & - & & & & & & \\
\hline Obs & 1604 & & & & & & \\
\hline Int. knowl & $0.1098^{*}$ & 1.0000 & & & & & \\
\hline$p$ values & 0.0000 & & & & & & \\
\hline Obs & 1604 & 1604 & & & & & \\
\hline Loc. knowl & 0.0550 & $0.2283^{*}$ & 1.0000 & & & & \\
\hline$p$ values & 0.0277 & 0.0000 & - & & & & \\
\hline Obs & 1604 & 1604 & 1604 & & & & \\
\hline $\mathrm{HH}$ income (log) & $0.1182^{*}$ & 0.0423 & -0.0034 & 1.0000 & & & \\
\hline$p$ values & 0.0000 & 0.0900 & 0.8931 & - & & & \\
\hline Obs & 1604 & 1604 & 1604 & 1604 & & & \\
\hline Male & 0.0461 & $-0.0983^{*}$ & $-0.1624^{*}$ & -0.0218 & 1.0000 & & \\
\hline$p$ values & 0.0648 & 0.0000 & 0.0000 & 0.3819 & - & & \\
\hline Obs & 1604 & 1604 & 1604 & 1604 & 1604 & & \\
\hline Rent (log) & $0.1349^{*}$ & $0.1781^{*}$ & $0.0767^{*}$ & $0.4739^{*}$ & $-0.1276^{*}$ & 1.0000 & \\
\hline$p$ values & 0.0000 & 0.0000 & 0.0021 & 0.0000 & 0.0000 & - & \\
\hline Obs & 1604 & 1604 & 1604 & 1604 & 1604 & 1604 & \\
\hline Education & $0.0969^{*}$ & $0.1490^{*}$ & $0.0647^{*}$ & $0.2557^{*}$ & -0.0231 & $0.2458^{*}$ & 1.0000 \\
\hline$p$ values & 0.0001 & 0.0000 & 0.0095 & 0.0000 & 0.3558 & 0.0000 & - \\
\hline Obs & 1604 & 1604 & 1604 & 1604 & 1604 & 1604 & 1604 \\
\hline
\end{tabular}

Table 3 Regression results

\begin{tabular}{|c|c|c|}
\hline & (1) & $(2)$ \\
\hline & Probit regression & Probit regression \\
\hline VARIABLES & Coefficients & Marginal effects \\
\hline \multicolumn{3}{|l|}{ Environmental consciousness/knowledge } \\
\hline International env. knowledge (dummy) & $0.27^{* * *}(0.089)$ & $0.06^{* * *}(0.019)$ \\
\hline Local/domestic env. knowledge (dummy) & $0.15^{*}(0.090)$ & $0.03^{*}(0.018)$ \\
\hline \multicolumn{3}{|l|}{ Controls } \\
\hline $\mathrm{HH}$ income (log) & $0.15^{* *}(0.059)$ & $0.03^{* *}(0.012)$ \\
\hline Male & $0.37^{* * *}(0.128)$ & $0.09^{* *}(0.034)$ \\
\hline Rent per month (log) & $0.14^{* * *}(0.054)$ & $0.03^{* * *}(0.010)$ \\
\hline Education (dummy) & $0.14^{*}(0.084)$ & $0.03^{*}(0.016)$ \\
\hline Constant & $-1.34^{* * *}(0.405)$ & \\
\hline District dummies & Yes & Yes \\
\hline Wald chi ${ }^{2}(15)$ & $73^{* * *}$ & \\
\hline Log pseudolikelihood & -584.03 & \\
\hline $\operatorname{AIC}(\mathrm{df}=16)$ & & 1200.051 \\
\hline $\mathrm{BIC}(\mathrm{df}=16)$ & & 1286.135 \\
\hline Observations & $1604^{1}$ & 1604 \\
\hline
\end{tabular}




\section{Results and discussion}

From Table 3, we sought to explore the extent to which households' consciousness of the environment will influence their behaviour regarding the choice of bulb for lighting. To achieve this, we created a dummy variable which was coded as 1 for those households who as of the time of the interview were using only energy-saving bulbs in their residence and 0 for those who were either combining incandescent bulbs with energy-saving bulbs or using only incandescent bulbs. This binary variable representing responses of the choice of bulb for lighting in residences by the household was used as the dependent variable. Given that the dependent variable is binary, we used both the probit and dprobit commands in STATA 14 to estimate the probit and marginal effect models, respectively. In this study, we explained environmental consciousness which is our variable of interest with knowledge of the environment. This is represented in two forms, namely local (domestic) environmental consciousness and international (global) environmental consciousness. We proxy the former with knowledge of domestic environmental issues (i.e. laws) and the latter with knowledge of climate change. In line with a priori expectation, we find environmental consciousness variables to be positive and statistically significant in explaining changes in the choice of light bulbs. Basing our analysis on the marginal effects in order to explore possible marginal effects, we observe that the parameter estimate for knowledge of climate change is 0.06 , suggesting that if knowledge of climate change rises from zero to one, the probability of choosing an energy-efficient bulb for lighting will rise by $6 \%$. Also, the parameter estimate for domestic environmental knowledge is 0.03 , implying that the probability of choosing an energy-efficient bulb for lighting will rise by $3 \%$ if knowledge of domestic environmental laws (or issues) rises from zero to one. This suggests that towards achieving efficient energy choices, one way by which households' behaviour can be in line with energy efficient choices somewhat depends on the extent to which they are environmentally conscious or informed.

In order to deal with biases associated with misspecification of our model, we introduced several control variables. These include income, male (gender), rent, education and district dummies. Except for district dummies, all other control variables were found to be positive and statistically significant.

In line with the consumer demand theory, income of the household was introduced in the model to capture the wealth of the household. With this, we expected that wealthy households will be willing to spend a fraction of their wealth to promote efficient energy choice. Consistent with our expectation vis-a-vis sign and significance, the marginal effect of 0.03 suggests that if income of the household rises by $1 \%$, the probability of the household willing to choose an energy-saving light bulb will increase by $3 \%$. This implies that consumers' choice for energysaving light bulbs is also influenced by income levels. Thus, higher income households are more likely to purchase energy-saving light bulbs, relative to lower income households. This is in line with studies such as Bertoldi and Atanasiu [18] and Di Maria et al. [3] that have shown that financial constraints and affordability counts in choosing energy-saving light bulbs.

Also, we expected that different physiological characteristics may influence consumer behaviour. So, we introduced gender into our model to evaluate the extent to which it will determine the choice of light bulbs. We found that males have a higher probability of choosing energy-saving light bulbs relative to females. Specifically, being a male compared to a female is associated with a $9 \%$ chance of choosing an energy-saving light bulb. This could be justified by the fact that in most African countries men are predominantly responsible for paying utility bills such as electricity and water among others. By this, one would expect the man to greatly influence the choice of light bulbs in their residence.

In the literature (see [19]), the size of residence has been used as a control variable. Similarly, in this study, we use the value of the residence rather than the size, as the value presents a broader picture of the residence than just the size. Generally, one would expect a good and energyfriendly environment to attract higher rent. That is, a residence with energy-saving facilities should be expected to attract higher property or rental value. Given that majority of people in the study area are renters, we included rental value to see its associated effect on consumer behaviour. With a marginal effect of 0.03 , we argue that if rental value should increase by $1 \%$ the probability that the household will choose an energy-saving light bulb is $3 \%$. Indeed, we have evidence that higher rental value properties are more likely to buy energy-saving light bulbs.

Education is considered in literature (see $[3,20]^{5}$ ) as an important variable that explains consumers' adoption decision. This helps consumers to predict almost correctly if not correctly the cost associated with using either an incandescent bulb or an energy-saving light bulb. Our results show a positive and statistically significant relationship between education and choosing to use energy-saving light bulbs in residences. Thus, we report a marginal effect coefficient of 0.03 suggesting that the probability of an educated household choosing an energy-efficient light bulb for lighting is $3 \%$ higher than an uneducated household. This finding is in line with construct validity.

\section{Conclusions}

This study provides highlights that the economic and environmental benefits for investing in energy-saving 
light bulbs cannot be overemphasized. It is an undoubted fact that much is expected from developing countries especially those in Africa and Asia. Amoah et al. [21] have substantiated this claim by arguing that Africa and Asia consist of $95 \%$ of the 1.4 billion people lacking access to electricity. However, we acknowledge that, indeed, some developing countries (e.g. Cuba, Venezuela, China, Thailand, Philippines, India, Egypt, Senegal, Ghana, etc.) have embarked on several policy measures towards expanding access to and adoption of efficient and sustainable clean energy use. A regional report on "Efficient Lighting in Sub-Saharan African [SSA] Countries" has shown that several countries have demonstrated high social acceptance for energy-efficient lighting technologies. For example, the report mentions that "[in] the survey conducted in Senegal, $95 \%$ of users were willing to adopt efficient technology" ([14], pg. 58). This follows a legislation in 2011, promoting energy-saving lighting. Also, Mexico is reported to have achieved energy efficiency, and one major reason underlying this achievement is attributed to the adoption of energy-saving light bulbs (see [22]). This is in line with the $86 \%$ shown by this study and the $79 \%$ reported by UNEP [14] on Ghana.

However, some of these developing countries, particularly Ghana, have not been able to expand its adoption to a hundred percent coverage in spite of conscious policy initiatives. This is observed to be the case because low income is a challenge to the adoption of new technology.

We hypothesize that environmental consciousness, awareness through education and subsidies to lower income groups can help expand use of energy-saving light bulbs in Ghana.

In this study, we used a representative sample of 1650 households. First, we undertook a series of diagnostic tests that are relevant in cross-sectional data analysis. Evidence from our empirical model estimation which is consistent with theoretical and existing empirical evidence suggests that environmental consciousness is one of the determinants in explaining the choice of light bulbs by households. In addition, we find demographic control variables such as education, income, rent and gender (male) having a positive and significant effect on choice.

By way of comparison, we acknowledge that the initial cost of buying energy-saving light bulbs is higher relative to its alternative. This has been a discouraging factor to majority of the people in developing countries whose income levels are generally very low. We propose to policy makers that given the fact that environmental consciousness and education are both relevant to consumers' behaviour, we recommend the use of these instruments to better inform households about the economic and environmental gains associated with energy-saving technologies. As advocated by Di Maria et al. [3] for developed countries, so do we advocate for developing countries. That is, "[t]he introduction of clearer energy labels, educational campaigns aimed at teaching consumers how to read them, or simply agreements with supermarkets and other retailers to clearly indicate the average cost per lumen of different types of light-bulbs, as commonly done for other products, would all speed the adoption of CFL's" (p.12). What needs to be stressed is the fact that the energy-saving technologies may be associated with higher initial costs but with time it is more cost efficient compared to energy costly technologies. Also, given that income is very sensitive to consumers' choice, we recommend governments' continual intervention through subsidies in making energy-saving technologies cheaper for adopters.

\section{Endnotes}

${ }^{1}$ See Bertoldi and Atanasiu [18] and Di Maria et al. [3] for benefits of CFLs.

${ }^{2}$ Education is not part of the disciplines mentioned in Schlegelmilch et al. [8]

${ }^{3}$ After the data collection, the districts have now been expanded to 16. Note: All ten districts were used.

${ }^{4}$ This study adopted only the second step used by Scott and Willits [13]. In their approach, they first used Dunlap and Van Liere's [23] approach with 12 items and further reduced the categories into three for easiness of analysis and descriptive purposes.

${ }^{5}$ This article was originally printed in 1978 by the Journal of Environmental Education. Therefore, the original reference has been used.

\section{Appendix}

Table 4 Principal component analysis/correlation

\begin{tabular}{lllll}
\hline Component & Eigenvalue & Difference & Proportion & Cumulative \\
\hline Comp1 & 1.75838 & 0.946621 & 0.5861 & 0.5861 \\
Comp2 & 0.811754 & 0.381883 & 0.2706 & 0.8567 \\
Comp3 & 0.429871 &. & 0.1433 & 1.0000 \\
\hline
\end{tabular}

No. of observations 1641, number of components $=3$, trace $=3$, rho $=1$

Table 5 Principal component (eigenvectors)

\begin{tabular}{llll}
\hline Variable & Comp1 & Comp2 & Comp3 \\
\hline Knowledge of climate change & 0.6052 & -0.4676 & 0.6442 \\
Knowledge of Kyoto Protocol & 0.4626 & 0.8652 & 0.1934 \\
Knowledge of global warming & 0.6049 & -0.1809 & -0.6399
\end{tabular}

*The other category was excluded as it basically repeated any of the items in the description 
Table 6 T test of choice of light bulb responses by international knowledge

\begin{tabular}{|c|c|c|c|c|c|c|}
\hline Group (knowledge of climate change) & Obs. & Mean & Std. err. & Std. dev. & \multicolumn{2}{|c|}{ [95\% conf. interval] } \\
\hline No & 620 & .8209677 & .0154093 & .3836889 & .7907069 & .8512286 \\
\hline Yes & 984 & .8973577 & .0096799 & .3036454 & .8783622 & .9163533 \\
\hline Combined & 1604 & .8678304 & .0084589 & .3387807 & .8512387 & .8844222 \\
\hline Difference & & -.07639 & .0172714 & & -.1102669 & -.0425131 \\
\hline diff $=$ mean $(0)-$ mean $(1)$ & & & & & \multicolumn{2}{|l|}{$t=-4.4229$} \\
\hline Ho: diff $=0$ & & & & & \multicolumn{2}{|c|}{ Degrees of freedom $=1602$} \\
\hline Ha: $\operatorname{diff}<0$ & & \multicolumn{3}{|l|}{ Ha: diff! $=0$} & \multicolumn{2}{|l|}{ Ha: diff >0 } \\
\hline $\operatorname{Pr}(T<t)=0.0000$ & & \multicolumn{3}{|c|}{$\operatorname{Pr}(|T|>|t|)=0.0000$} & \multicolumn{2}{|c|}{$\operatorname{Pr}(T>t)=1.0000$} \\
\hline
\end{tabular}

Table $7 T$ test of choice of light bulb responses by local knowledge

\begin{tabular}{|c|c|c|c|c|c|c|}
\hline Group (local knowledge) & Obs. & Mean & Std. err. & Std. dev. & \multicolumn{2}{|c|}{ [95\% conf. interval] } \\
\hline No & 705 & .8468085 & .0135745 & .3604277 & .8201572 & .8734598 \\
\hline Yes & 899 & .8843159 & .0106734 & .3200238 & .8633682 & .9052636 \\
\hline Combined & 1604 & .8678304 & .0084589 & .3387807 & .8512387 & .8844222 \\
\hline Difference & & -.0375074 & .0170226 & & -.0708962 & -.0041186 \\
\hline diff $=$ mean $(0)-$ mean $(1)$ & & & & & \multicolumn{2}{|l|}{$t=-2.2034$} \\
\hline Ho: diff $=0$ & & & & & \multicolumn{2}{|c|}{ Degrees of freedom $=1602$} \\
\hline Ha: diff $<0$ & & Ha: diff! $=0$ & & & \multicolumn{2}{|l|}{ Ha: diff $>0$} \\
\hline $\operatorname{Pr}(T<t)=0.0139$ & & $\operatorname{Pr}(|T|>|t|)=$ & & & \multicolumn{2}{|c|}{$\operatorname{Pr}(T>t)=0.9861$} \\
\hline
\end{tabular}

\section{Abbreviations}

CFL: Compact florescent lamps; GAR: Greater Accra Region; SDGs: Sustainable Development Goals

\section{Acknowledgements}

The authors are grateful to the School of Economics, University of East Anglia, UK, and Central University, Ghana, for supporting this study. The authors are grateful to the two anonymous reviewers and the editorial team for their useful comments that have improved the paper. All errors remain as those of the authors.

\section{Availability of data and materials}

Data and additional materials are available on request.

\section{Authors' contributions}

All sections of the study including concepts, designs, fieldwork, write-up and proofreading were jointly done by the authors. The names of the authors have therefore been presented in alphabetical order. All authors read and approved the final manuscript.

\section{Competing interests}

The authors declare that they have no competing interests.

\section{Publisher's Note}

Springer Nature remains neutral with regard to jurisdictional claims in published maps and institutional affiliations.

Received: 11 October 2017 Accepted: 5 April 2018

Published online: 21 May 2018

\section{References}

1. Energy Commission, Ghana (2009) Final report-CFL exchange programme impact assessment. Available at http://www.energycom.gov.gh/files/ CFL\%20Report\%20final.pdf. Accessed on the 6 Feb 2017
2. Gately D (1980) Individual Discount Rates and the Purchase and Utilization of Energy-Using Durables: Comment. Bell J Econ, The RAND Corporation 11(1):373-374

3. Di Maria C, Ferreira S, Lazarova E (2010) Shedding light on the light bulb puzzle: the role of attitudes and perceptions in the adoption of energy efficient light bulbs. Scott J Pol Econ 57(1):48-67

4. Ellen PS (1994) Do we know what we need to know? Objective and subjective knowledge effects on pro-ecological behaviors. J Bus Res 30(1):43-52

5. Asilsoy BA (2012) Survey study on environmental consciousness in Famagusta. Procedia-Soc Behav Sci 35:675-681

6. Kaynak R, Ekşi S (2014) Effects of personality, environmental and health consciousness on understanding the anti-consumptional attitudes. Procedia-Soc Behav Sci 114:771-776

7. Sánchez M, López-Mosquera N, Lera-López F (2016) Improving proenvironmental behaviours in Spain. The role of attitudes and sociodemographic and political factors. J Environ Policy Plann 18(1):47-66

8. Schlegelmilch BB, Bohlen GM, Diamantopoulos A (1996) The link between green purchasing decisions and measures of environmental consciousness. Eur J Mark 30(5):35-55

9. Van Liere KD, Dunlap RE (1981) Environmental concern: does it make a difference how it's measured? Environ Behav 13(6):651-676

10. Buttel FH (1979) Age and environmental concern: a multivariate analysis. Youth Soc 10(3):237-256

11. Brooker $G$ (1976) The self-actualizing socially conscious consumer. J Consum Res 3:107-112

12. Amoah A (2017) Demand for domestic water from an innovative borehole system in rural Ghana: stated and revealed preference approaches. Water Policy J 19(1):46-68

13. Scott D, Willits FK (1994) Environmental attitudes and behavior: a Pennsylvania survey. Environ Behav 26(2):239-260

14. United Nations Environment Programme (UNEP) (2012) Regional report on efficient lighting in sub-Saharan African countries. Available at http:// united4efficiency.org/wp-content/uploads/2016/09/en.lighten_Sub-SaharanReport.pdf. Accessed on the 6 Feb 2017

15. Masters WA, Garcia AF (2010) Agricultural price distortions and stabilization. Pol Econ Agric Price Distortions 30:215-240 
16. Amoah A, Moffatt GP (2016) Estimating demand for reliable piped-water services in urban Ghana: an application of competing valuation approaches. Working Paper Series, 2017-01 School of Economics, University of East Anglia, UK. Available at https://ideas.repec.org/p/uea/ueaeco/2017_01.html. Accessed 6 Feb 2017

17. Englin J, Cameron TA (1996) Augmenting travel cost models with contingent behavior data. Environ Resour Econ 7(2):133-147

18. Bertoldi P, Atanasiu B (2006) Residential lighting consumption and saving potential in the enlarged EU, Working paper. European Commission, DG Joint Research Centre, Institute for Environment and Sustainability

19. Mills B, Schleich J (2008) Why don't households see the light?: explaining the diffusion of compact fluorescent lamps. Working paper 2008-09, Virginia Tech

20. Dunlap RE (2008) The new environmental paradigm scale: from marginality to worldwide use. J Environ Educ 40(1):3-18

21. Amoah A, Larbi DA, Offei D, Panin A (2017) In gov we trust: the less we pay for improved electricity supply in Ghana. Energy Sustainability Soc 7(1):29

22. Gevorkian P (2017) Grid-connected photovoltaic power generation. Cambridge University Press

23. Dunlap RE, Van Liere KD (1978) The "new environmental paradigm". J Environ Educ 9(4):10-9

\section{Submit your manuscript to a SpringerOpen ${ }^{\odot}$ journal and benefit from:}

- Convenient online submission

Rigorous peer review

- Open access: articles freely available online

- High visibility within the field

- Retaining the copyright to your article

Submit your next manuscript at $\gg$ springeropen.com 